\title{
Poly(vinyl trimethylsilane) and block copolymers of vinyl trimethylsilane with isoprene: Anionic polymerization, morphology and gas transport properties
}

\author{
Sofia Rangou, Sergey Shishatskiy*, Volkan Filiz, Volker Abetz* \\ Institut für Polymerforschung, Helmholtz-Zentrum Geesthacht, Max-Planck-Str. 1, 21502 Geesthacht, Germany
}

\section{A R T I C L E I N F O}

\section{Article history:}

Available online $\mathrm{xxxx}$

Dedicated to Professor Nikos Hadjichristidis in recognition of his contribution to polymer science.

\section{Keywords:}

PVTMS

PI- $b$-PVTMS

Anionic polymerization

Block copolymer

Morphology

Membrane

\begin{abstract}
A B S T R A C T
Poly(vinyl trimethylsilane) (PVTMS) and block copolymers of vinyl trimethylsilane with isoprene were synthesized by anionic polymerization and characterized. The synthesized pure PVTMS has properties similar to a reference material produced about two decades ago and can be used for thin film composite membrane formation. Even at low isoprene content the block copolymers have improved film forming properties compared to the pure PVTMS. However, the presence of the isoprene units in the block copolymers leads to a decrease of the gas permeability but does not affect the selectivity of the membranes $\left(\alpha\left(\mathrm{O}_{2} / \mathrm{N}_{2}\right)=3.9\right)$.
\end{abstract}

(c) 2010 Elsevier Ltd. All rights reserved.

\section{Introduction}

Processes involving polymeric membranes for separation of air components meet much attention from industry. The development of new types of membranes can open an opportunity of membrane based process implementation in the areas where it was not considered to be used before.

Most of the processes of air separation do not require extreme selectivities or permeances. For example, shift of the oxygen concentration from $21 \%$ to $50 \%$ or nitrogen concentration from $78 \%$ to $85 \%$ are sufficient for such applications as controlled burning, food storage etc.

Poly(vinyl trimethylsilane) (PVTMS) is known for more than 40 years as a polymer with a reasonable $\mathrm{O}_{2}$ permeability (40-44 Barrer) and good $\mathrm{O}_{2} / \mathrm{N}_{2}$ selectivity $\left(\alpha\left(\mathrm{O}_{2} /\right.\right.$ $\mathrm{N}_{2}$ ) =4.0) [1]. Integral asymmetric membranes made of PVTMS were industrially produced and used in the Soviet Union and France [2-4]. As far as we know PVTMS was

\footnotetext{
* Corresponding authors.

E-mail addresses: sergey.shishatskiy@hzg.de (S. Shishatskiy), volker. abetz@hzg.de (V. Abetz).
}

so far the only polymer produced solely as a membrane material. Unfortunately the production of PVTMS was stopped with the collapse of the USSR.

The PVTMS integral asymmetric membrane has had several drawbacks related to the polymer properties as well as the membrane structure. Its small elongation at break $(\varepsilon=5 \%$ ) [2-4] has lead to brittleness of the membrane; both selective top layer and porous supporting structure were formed from the same polymer leading to a high consumption of PVTMS. The thickness of the selective layer was too large providing $\mathrm{O}_{2}$ permeance not more then $\mathrm{P}\left(\mathrm{O}_{2}\right)=0.4 \mathrm{Nm}^{3} \mathrm{~m}^{-2} \mathrm{~h}^{-1}$ bar $^{-1}$ with the $\mathrm{O}_{2} / \mathrm{N}_{2}$ selectivity slightly lower than the intrinsic one.

The modern state of membrane technology provides one with the possibility to form defect free selective layers having thicknesses below $100 \mathrm{~nm}$ for both integral asymmetric and thin film composite (TFC) membranes. TFC membranes give the advantage to use expensive selective layer materials since the consumption of the material will usually not exceed $0.2 \mathrm{~g} \mathrm{~m}^{-2}$. It opens the possibility to use experimental or tailor made polymers for membranes produced in industrial scale. [5]. 
The current work has pursued the aim to restart the PVTMS synthesis and bring it again into praxis as gas separation membrane material. Homopolymer as well as block copolymers with polyisoprene were synthesized and characterized for various properties.

Several attempts have been made so far to improve the poor mechanical properties of the PVTMS. Gladkova et al. have synthesized copolymers of poly(vinylmethyl trivinylsilane) with poly(dimethyl siloxane) (PVTMS-b-PDMS) since they were considered the most promising membrane materials with enhanced gas permeability and separation selectivity. The technique followed was sequential anionic polymerization in tetrahydrofuran (THF) using sec-Butyllithium (BuLi) as initiator. [6].

A further study of this combination of polymeric chains reports the successful synthesis of triblock copolymers of the ABA type (PDMS- $b$-PVTMS- $b$-PDMS) in THF using as initiator for the PVTMS difunctional block, dilithium naphthalene. [7].

Statistical and sequential copolymers consisting of styrene and vinyl trimethylsilane units were investigated as well. The synthesis of such polymeric materials was conducted in heptane with $n$-BuLi as initiator. From this study the much faster polymerization of styrene was concluded since the constant of the copolymerization parameter is $5.7 \pm 0.03$, while that of vinyl trimethylsilane is $0.06 \pm 0.01$ [8].

An additional attempt to improve the mechanical properties of PVTMS homopolymer was done by the sequential copolymerization of VTMS with butadiene (PB- $b$-PVTMS) by anionic polymerization induced by mono- and dilithium compounds. [9].

In the current work isoprene was chosen as a comonomer since it is a purely organic polymer with excellent film forming properties and rather high gas permeability as well as $\mathrm{O}_{2} / \mathrm{N}_{2}$ selectivity. It was expected that the resulting block copolymers will lead to less brittle films due to the mechanical properties of polyisoprene. Thus film formation should be improved without significant drop in gas permeability and selectivity.

\section{Experimental part}

\subsection{Materials}

Vinyl trimethylsilane (99\% pure) was purchased from ABCR GmbH. Isoprene and cyclohexane both of $99 \%$ purity was purchased from Sigma-Aldrich International. All monomers and solvents were further purified to the standards required for anionic polymerization. The initiator $n$-BuLi 1.6 $\mathrm{M}$ in hexane was purchased from Acros Organics and used without further purification.

Oxygen and nitrogen with purity $99.999 \%$ were purchased from Linde AG and used as received.

\subsection{Polymer synthesis and purification}

In order to achieve the synthesis of both homo- and copolymers all materials were purified to anionic polymerization standards $[10,11]$. In the case of copolymerization of isoprene and VTMS the procedure followed is given in details: $40 \mathrm{ml}$ (27.6 g) of vinyl trimethylsilane were dried first over calcium hydride for $24 \mathrm{~h}$ at reduced temperature under vacuum. After two freeze-degas cycles it was condensed in a flask containing sodium mirror, made from $1 \mathrm{~g}$ of sodium by warming the sodium in the evacuated vessel, and left for $1 \mathrm{~h}$ to react. $4 \mathrm{ml}$ ( $2.68 \mathrm{~g}$ ) of isoprene were dried to anionic standards as previously referred in the literature [11]. Cyclohexane was used as solvent in all polymerizations and was purified by redistillation in the presence of liquid sodium under inert atmosphere, and after freezing and degassing, transferred under vacuum in a flask containing oligomers of polystyryllithium where it was kept. The red color of living polystyryllithium oligomers in cyclohexane was indicative for the purity of the solvent. It is important at this point to mention that the homopolymerization of VTMS or copolymerization of VTMS with isoprene was successful only in the case of high vacuum conditions. First the initiator $\left(0.08 \times 10^{-3}\right.$ moles $n$-BuLi $1.6 \mathrm{M}$ in hexane) was inserted into the vacuum dried polymerization reactor under inert atmosphere followed by thorough drying of the solvent. Then it was rediluted with cyclohexane used for the polymerization. The amount of solvent used in all polymerization reactions was equal to the volume of the VTMS monomer since, as it was observed during our very first attempts and also reported in the literature; a high monomer concentration is required for this slowly polymerizing system.

Isoprene was inserted into the polymerization reactor and left to complete conversion according to the kinetics proposed by Bywater for the polymerization of isoprene with $n$-BuLi in cyclohexane.[12] The addition of VTMS was achieved by distillation into the reactor, and the reaction was left to complete for six days at $35^{\circ} \mathrm{C}$ [13]. During the polymerization reaction there were no samples removed and after the completion the polymer was precipitated into excess of methanol only once. Previous works describe the dilution and precipitation at least three times to separate all lower molecular weight fractions, but in this way the cost of production rises and our goal was to follow a procedure as close as possible to industrial production.

In another approach, both monomers were added to the reactor before initiation. The procedure of drying the initiator and purification of materials was exactly the same as before and the amounts of monomers and solvents were kept the same in order to have a comparison between the conversions of the two monomers.

\subsection{Polymer characterization}

Gel permeation chromatography (GPC) measurements were performed at room temperature in THF using $5 \mu$ PSS SDV gel columns $\left(10^{2}, 10^{3}, 10^{4}, 10^{5} \AA, 8.300 \mathrm{~mm}\right.$ each, PSS $\mathrm{GmbH}$, Mainz, Germany) at a flow rate of $1.0 \mathrm{ml} / \mathrm{min}$ (VWR-Hitachi 2130 pump). A Waters 2410 refractive index detector $(\lambda=930 \mathrm{~nm})$ and a Waters UV-photometer (typically operated at $\lambda=254 \mathrm{~nm}$ ) were used for concentration detection. Samples were injected employing a Waters 717 autosampler (injection volume $50 \mu \mathrm{L}$ ). To compensate for flow-rate fluctuations 20 ppm 2,6-di-tert-butyl-hydroxytoluene (BHT) was added as internal standard to each sample. Raw data were processed using PSS WinGPC Unity 
software package. Elugrams are flow-rate corrected; polystyrene calibration was used to calculate the apparent molecular weight distribution and the corresponding averages.

Static light scattering was performed on a ALV-CGS 3 using a laser with a wavelength of $633 \mathrm{~nm}$.

All proton nuclear magnetic resonance $\left({ }^{1} \mathrm{H}-\mathrm{NMR}\right)$ measurements were performed on a Bruker Advance 300 NMR spectrometer with $300 \mathrm{MHz}$ without internal standard (TMS) using $\mathrm{CDCl}_{3}$ as a solvent.

Transmission electron micrographs were taken with a Tecnai G2 F20 (FEI) operated at $200 \mathrm{kV}$ in the bright field mode. Ca. $50 \mathrm{~nm}$ thick sample films were obtained by microtoming membrane films at room temperature, which were embedded in epoxy. The films were then stained with $\mathrm{OsO}_{4}$ to visualize polyisoprene domains. As in one case not clear images could be gained by TEM, also synchrotron SAXS at the A2-beamline of DESY was carried out on one cast membrane film.

\subsection{Membrane formation}

The synthesized polymers were dissolved in toluene as the best solvent for both PVTMS and polyisoprene. The polymer concentration was maintained below 4 wt.\% in order to work with polymer solutions of low viscosity and to have enough solvent for filling the membrane casting setup with the layer of solution being thick enough for slow (at least $48 \mathrm{~h}$ ) evaporation.

The membrane casting setup consisted of an $80 \mathrm{~mm}$ diameter aluminium ring with polished upper and bottom sides, glass plate coated with the Bytac ${ }^{\circledR}$ Teflon $^{\circledR}$ coated aluminium foil and leveled table. The polymer solution was filtered through a fine cotton filter and poured into the aluminium ring placed on the Teflon ${ }^{\circledR}$ surface. The ring was covered with a glass lid having openings for the gas connection and ventilation. Nitrogen gas stream $\left(10 \mathrm{ml} \mathrm{min}^{-1}\right)$ was used to remove toluene vapor from the casting setup. Solvent evaporation was carried out at room temperature. When there were no indications of presence of toluene, the obtained membrane was mechanically removed from the Teflon surface and placed into the vacuum oven where it was evacuated for at least $4 \mathrm{~h}$ at $100{ }^{\circ} \mathrm{C}$ in vacuum provided by the turbomolecular pumping unit. Only membranes with a thickness deviation less than $5 \mu \mathrm{m}$ as determined by using a Fischer Deltascope ${ }^{\circledR}$ FMP10 instrument were used for the characterization of gas transport properties.

\subsection{Density}

Polymer density was determined for the membrane samples prepared for gas permeation tests. Hydrostatic weighting was performed in a setup consisting of a Sartorius R200D microbalance ( $0.00001 \mathrm{~g}$ accuracy) combined with Sartorius 6080 specific gravity determination kit.[14] 3 M FC77 perfluorinated liquid was used as a media for buoyancy determination since this high density liquid $\rho=1.772 \mathrm{~g} \mathrm{~cm}^{-3}$ ) has no affinity to any organic polymer and has a very low surface tension.

\subsection{Gas transport properties}

$\mathrm{O}_{2}$ and $\mathrm{N}_{2}$ permeability coefficients were determined on the constant volume variable pressure experimental setup described elsewhere [15]. Measurements were carried out at $30^{\circ} \mathrm{C}$ at least 4 times for each gas. The results with the error less than $\pm 3 \%$ were taken into account.

\section{Results and discussion}

\subsection{Polymer synthesis and basic characterization}

The molecular characterization of the samples proved the successful synthesis of all three types of polymeric materials. The homopolymerization of PVTMS was known long ago [13], but according to our knowledge the sequential and simultaneous copolymerization with isoprene has never been reported in the literature. In the case of copolymerization with isoprene its actual percentage was calculated from ${ }^{1} \mathrm{H}$-NMR results. For the polyisoprene chain the calculated chemical shifts are attributed to the following olefinic protons according to the geometric isomerism of the polymeric chain: $1 \mathrm{H}$ of the polyisoprene- 1,4 geometric isomerism at $\delta$ : $5.12 \mathrm{ppm}(-\mathrm{CH}=), 2 \mathrm{H}$ from the polyisoprene-3,4 geometric isomerism at $\delta: 4.70 \mathrm{ppm}$ $\left(-\mathrm{CH}_{3}\right), 1 \mathrm{H}$ at $5.82 \mathrm{ppm}(-\mathrm{CH}=)$ and $2 \mathrm{H}$ at $\delta: 5.00 \mathrm{ppm}$ from the polyisoprene-1,2 geometric isomerism $\left(=\mathrm{CH}_{2}\right)$ [16]. The polyisoprene is predominantly composed of 1,4 microstructure and around 8\% 3,4-microstructure. The chemical shifts found for the PVTMS are attributed as followed: $9 \mathrm{H}$ at $\delta: 0.03 \mathrm{ppm}\left(\mathrm{SiMe}_{3}\right), 1 \mathrm{H}$ at $\delta: 0.85 \mathrm{ppm}$ $(\mathrm{CH})$, and $2 \mathrm{H}$ at $\delta: 1.47 \mathrm{ppm}\left(\mathrm{CH}_{2}\right) \cdot[17]$.

The sequential and simultaneous anionic polymerization of isoprene and VTMS led to polymers with molecular weights similar to the ones calculated, and the yield of polymerization was in both cases ca. $75 \%$ for the VTMS monomer leading to a minor change in the expected molecular weight of PVTMS block.

Due to the rapid polymerization of isoprene compared to the kinetics of VTMS the copolymerization of the two monomers has less statistical distribution and leads basically to a diblock copolymer structure, as indicated by the morphological properties discussed later. However, the details of this anionic copolymerization need further investigation.

All molecular characteristics are summarized in Table 1. As observed in the table but is also mentioned in the literature [13] the polydispersity index (PDI) is higher than expected for this type of polymerization (1.4-2 instead of polydispersities close to 1-1.1). Higher molecular weight PVTMS studied by Nametkin et al. [13] contain to a small extent $(2-3 \%)$ slightly branched architectures, leading to diffusion into the columns and broader polydispersities. Moreover the $n$-BuLi intitated polymers are considered to self terminate at low conversion which would appear in the molecular weight distribution curve as a low molecular tail [13]. Weight averaged molecular weights were confirmed by static light scattering in THF solution at $30^{\circ} \mathrm{C}$ and the difference found was close to $10 \%$ from the ones calculated by GPC, thus the deviation did not exceed the 
Table 1

Molecular characteristics of pure PVTMS and PVTMS- $b$-PI block copolymers.

\begin{tabular}{lclll}
\hline Sample & $\begin{array}{l}\bar{M}_{n}{ }^{\mathrm{a}} \\
(\mathrm{kg} / \mathrm{mol})\end{array}$ & $\begin{array}{l}\bar{M}_{w}{ }^{\mathrm{a}} \\
(\mathrm{kg} / \mathrm{mol})\end{array}$ & $\bar{M}_{w} / \bar{M}_{n}{ }^{\mathrm{a}}$ & $\begin{array}{l}\text { \% weight } \\
\text { PI content }^{\mathrm{b}}\end{array}$ \\
\hline PVTMS-ref & 350 & 650 & 2.1 & - \\
PVTMS-149 & 85 & 150 & 1.7 & - \\
PVTMS-190 & 86 & 190 & 2 & - \\
PI-sim-PVTMS-116 & 70 & 120 & 1.6 & 5 \\
PI-sim-PVTMS-130 & 84 & 130 & 1.5 & 24 \\
PI-seq-PVTMS-120 & 73 & 120 & 1.6 & 7 \\
PI-seq-PVTMS-166 & 100 & 170 & 1.6 & 26 \\
\hline
\end{tabular}

sim: VTMS and isoprene were initiated simultaneously.

seq: Isoprene was polymerized first and then VTMS was added as the second monomer.

a GPC in THF at $30^{\circ} \mathrm{C}$ calibrated with polystyrene standards.

b Weight fractions calculated from ${ }^{1} \mathrm{H}$ NMR in $\mathrm{CDCl}_{3}$ without using TMS as internal standard.(92 wt.\% 1.4 microstructure and $8 \mathrm{wt} \% \quad 3.4$ microstructure).

error of the molecular weight determination by the GPC method. GPC was calibrated to polystyrene standards. The deviation from the universal calibration parameters in this case is negligible since PVTMS belongs to the class of flexible polymers similar to polystyrene as stated in the literature. [13] All results given in the following Table 1 are not corrected, in order to make easier the comparison with already published results [13].

As a reference material the PVTMS recovered from the industrially produced integral asymmetric membrane was used [18]. The membrane was dissolved in toluene; the solution was filtered with a $25 \mu \mathrm{m}$ stainless steel filter in order to remove dust and not dissolved PDMS which was used to seal membrane defects according to the Henis and Tripody approach [19]. About $30 \mathrm{wt} . \%$ of methanol with respect to the polymer solution in toluene was added to bring it close to the cloud point line. The obtained solution containing about $10 \mathrm{wt} . \%$ of PVTMS was slowly poured into the beaker filled up with the methanol in quantity 10 -fold more then the amount of polymer solution. The precipitated polymer was transferred into another beaker with fresh methanol for complete solvent exchange. After 24hours the polymer was removed from the methanol and dried at $100{ }^{\circ} \mathrm{C}$ in vacuum.

The GPC investigation has shown that the reference PVTMS (PVTMS-ref) has a molecular weight of 500 $\mathrm{kg} \mathrm{mol}^{-1}$ and a PDI of 2.1. The NMR study did not show any peaks attributable to other materials such as PDMS insuring us in the purity of the PVTMS-ref.

The membrane prepared from PVTMS-ref was completely transparent and was easily breakable with the formation of "silver cracks" when bent or cut with the ring knife for gas transport tests. After the gas transport tests membranes had a large number of "silver cracks" at the area of contact with the polymeric sealing ring used to seal the measurement cell of the experimental facility. The same behavior was observed for all studied samples of pure PVTMS and copolymers having polyisoprene contents below $10 \mathrm{wt} . \%$.

In Table 2 the properties of all homo and copolymers are summarized. The glass transition temperature of poly(1,4-isoprene) is around $-80^{\circ} \mathrm{C}[20,21]$, while the glass transition temperature of PVTMS is reported in the literature in a range from $105-144{ }^{\circ} \mathrm{C}$. [22] The thermal behavior of this polymer is more complex due to the existence of possible mesophases [23].

\subsection{Morphology of the block copolymer membranes}

The morphology of copolymers resulting from simulataneous polymerizations of mixtures of VTMS and isoprene having relative amounts of 5 and $24 \mathrm{wt}$.\% of isoprene were studied by the transition electron microscopy. The samples for the TEM investigations were prepared from the same membrane samples which were used for the gas transport characterization measurements. Their typical thickness was in the range of about $100 \mu \mathrm{m}$. The investigation has revealed strong microphase separation of the polyisoprene and PVTMS blocks. At $5 \mathrm{wt}$ \% polyisoprene forms dispersed domains in the PVTMS matrix. The morphology could not be clearly visualized by TEM, so synchrotron SAXS was applied to this sample (Fig. 1a). The relative peak positions $\mathrm{q}^{*} / \mathrm{q}_{1}$ at $1 / 3^{1 / 2}$ may indicate a hexagonal packing with a periodicity of $76 \mathrm{~nm}$, which would indicate a very strong segretation between the two blocks, as typically for this composition a spherical domain structure would be expected. In any case these peaks prove a microphase separation between the two blocks. A copolymer with the 24 wt.\% of polyisoprene forms a well defined lamellar structure with a characteristic PVTMS lamellae thickness of $70 \mathrm{~nm}$ and a long period above $100 \mathrm{~nm}$, which could not be resolved by SAXS. For that reason the morphology a TEM micrograph of that sample is shown in Fig. 1b. This also indicates a very strong segregation between the two

Table 2

Properties of the pure PVTMS and PVTMS- $b$-PI block copolymers.

\begin{tabular}{|c|c|c|c|c|c|}
\hline Sample & Density, $\mathrm{g} \mathrm{cm}^{-3}$ & Error of density determination, $\mathrm{g} \mathrm{cm}^{-3}$ & FFV, \% ${ }^{a}$ & $\mathrm{P}\left(\mathrm{O}_{2}\right)$, Barrer ${ }^{\mathrm{b}}$ & $\alpha\left(\mathrm{O}_{2} / \mathrm{N}_{2}\right)$ \\
\hline PVTMS-ref & 0.875 & - & 21.1 & 48 & 3.9 \\
\hline PVTMS-149 & 0.875 & 0.001 & 21.3 & 56 & 3.7 \\
\hline PVTMS-190 & 0.880 & - & 21.3 & 51 & 3.9 \\
\hline PI-sim-PVTMS-116 & 0.885 & 0.001 & 20.3 & 29 & 3.9 \\
\hline PI-sim-PVTMS-130 & 0.892 & 0.001 & 19.2 & 27 & 3.8 \\
\hline PI-seq-PVTMS-120 & 0.882 & 0.001 & 20.5 & 30 & 4.0 \\
\hline PI-seq-PVTMS-166 & 0.898 & 0.002 & 18.6 & 22 & 3.8 \\
\hline
\end{tabular}

a FFV Fractional free volume.

b 1 Barrer $=1 \times 10^{10} \mathrm{~cm}^{3}(\mathrm{STP}) \mathrm{cm} \mathrm{cm}^{-2} \mathrm{~s}^{-1} \mathrm{~cm} \mathrm{Hg}^{-1}=7.52 \times 10^{-15} \mathrm{~m}^{3}(\mathrm{STP}) \mathrm{m} \mathrm{m}^{-2} \mathrm{~s}^{-1} \mathrm{kPa}^{-1}$. 
(a)

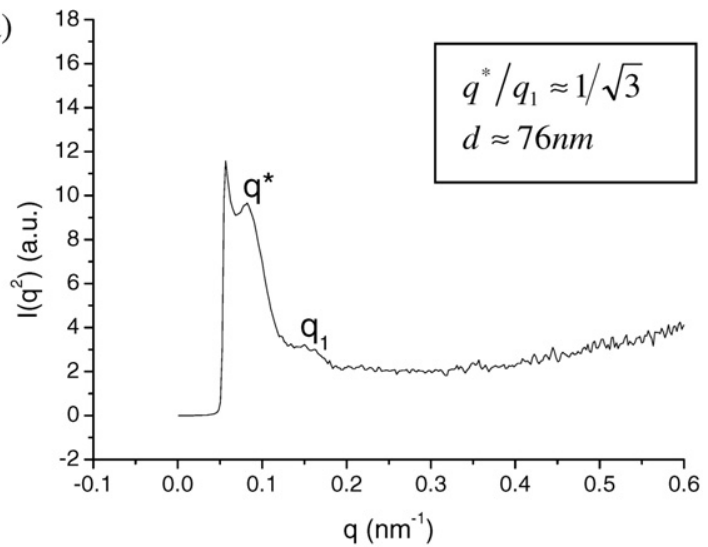

(b)

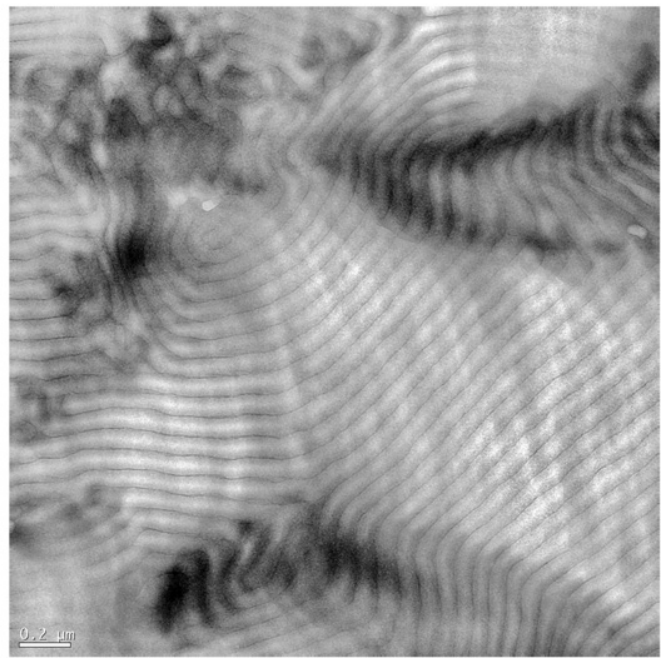

Fig. 1. SAXS of the $5 \mathrm{wt} . \%$ (a) and TEM micrograph of $24 \mathrm{wt} . \%$ (b) copolymers obtained by simultaneous polymerization of isoprene and VTMS. The dark phase corresponds to the polyisoprene microdomains. The scale bar correspond to $200 \mathrm{~nm}$.

blocks, as for such a composition in most diblock copolymers a cylindrical morphology would be expected. These results clearly confirm the formation of block copolymers, even when both types of monomers are present in the polymerization reaction from the very beginning. The fact that hexagonal and lamellar structures are found for these relatively low contents of polyisoprene, may be an indication of the tendency of PVTMS to form liquid crystalline phases, as was discussed before [18]. It has also been shown theoretically that block copolymers of a liquid crystalline block and an amorphous block tend to form lamellar structure over larger compositional ranges as compared to block copolymers composed of two amorphous blocks [24].

\subsection{Membrane transparency}

All pure PVTMS membranes were completely transparent. Also the block copolymers were transparent for the eye observation when the polyisoprene content is below $10 \mathrm{wt}$.\%. Block copolymers with more the $20 \mathrm{wt} . \%$ polyisoprene were loosing their transparency depending on the synthetic route: block copolymers obtained via simultaneous polymerization appeared slightly homogeneously milky, while the block copolymers obtained from sequential addition of the two types of monomers had a visible grain structure, indicating macroscopic grains. A possible explanation could be a certain gradient concentration profile along the chain in the case of the simultaneous copolymerization or even the presence of a very small amount of isoprene units in the PVTMS matrix domain, while the sequential addition of the VTMS after complete conversion of isoprene lead to a sharp concentration change at the block junction. Thus the level of microphase separation achieved in the equilibrium state should be weaker in the "simultaneous" case. Microphase separation of a homogeneously dissolved block copolymer will occur during the evaporation of the solvent, as the solvent's ability to screen repulsive interactions between dissimilar blocks will disappear below a certain solvent concentration. However, the degree of order during the self-assembling process will depend both on thermodynamic and kinetic factors. Besides the degree of incompatibility (i.e. the segregation strength due to repulsive segmental interactions) and the rate of solvent evaporation also the mobility of the chain segments will play a role and the question, if the block copolymer in the dry state is in a solid or liquid (melt) state, where it can further relax. Since the glass transition temperature of PVTMS is much above room temperature, the block copolymer structure will not further equilibrate, once during the evaporation of the solvent the glass transition temperature of the PVTMS-solvent mixture increases above the actual temperature of the thin film, which might be well below the environmental temperature due to the negative heat of evaporation. From this it can be expected that the formation of a thin film composite (TFC) membranes of such block copolymers might suppress the formation of long-range ordered microphases by an extremely fast evaporation of the solvent. The formation and properties of these TFC membranes will be studied in future.

\subsection{Molecular weight and film formation}

As it was indicated before the molecular weight of the PVTMS-ref is in the order of $500 \mathrm{~kg} \mathrm{~mol}^{-1}$. A high molecular weight was required for the formation of the integral asymmetric membrane where PVTMS has to provide the integrity of the selective layer, the mechanical stability of the supporting porous structure and the overall membrane processability. In case of the TFC membranes the mostly required property of the PVTMS is its ability to form defect free thin films and to have the macromolecular size big enough not to penetrate into the porous support made of other materials.

A number of PVTMS samples having different molecular weights in the range of 22 to $190 \mathrm{~kg} \mathrm{~mol}^{-1}$ were synthesized. It was found that for a molecular weight of approx. $150 \mathrm{~kg} / \mathrm{mol}$ or higher, the pure PVTMS forms a stable membrane which could withstand the cutting and consequent pressing and exposition to a break-through like gas pressure change in the measurement cell of the gas permeation facility. 
The presence of the PIs in the polymer gave a positive effect on the film forming properties. Already at $M_{\mathrm{w}}=120$ $\mathrm{kg} \mathrm{mol}^{-1}$ both "simultaneous" and "sequential" block copolymers formed perfectly processable membranes. The membranes were flexible and withstand the cutting well.

\subsection{Polymer density}

The density of the PVTMS-ref is in a good agreement with the previously published data [14], indicating that the polymer recovered from different integral asymmetric membrane batches has constant properties. Newly synthesized polymers able to form stable membranes have shown the same density as the reference material, indicating the similar polymer chain packing. Introduction of the polyisoprene blocks into the polymer chain leads to an increase of density, which depends on the amount of polyisoprene. The density of polyisoprene $\left(\rho=0.913 \mathrm{~g} \mathrm{~cm}^{-3}\right)$ [25] is thus higher than the one of PVTMS $\left(\rho=0.875 \mathrm{~g} \mathrm{~cm}^{-3}\right)$ and the rise of the density in case of the block copolymers was to be expected.

Fractional free volume (FFV) was calculated for the pure PVTMS and PI according to the Bondi approach [26], in case of the block copolymers the occupied volume was calculated by an additive scheme from the polyisoprene content while density was used for specific volume determination. All copolymers have FFV lower then pure PVTMS and the FFV decreases with increasing polyisoprene content. The FFV data are in compliance with the $\mathrm{O}_{2}$ permeability data: lower FFV leads to lower permeability.

\subsection{Gas transport properties}

PVTMS-ref has very stable gas transport properties, which do not change significantly over time. Once prepared the PVTMS membrane can be used for the equipment calibration for a time period as long as years. This makes this polymer distinct from many other newly discovered glassy polymers having excellent gas transport properties which cannot find their way into industrial gas separation because of aging, one of the issues most discussed in membrane science. The aging of glassy polymers is one of the reasons why just about 10 polymers are used nowadays for permanent gas selective membrane production [27] and the reason to bring PVTMS into membrane technological applications.

The properties of the PVTMS-ref allows one to reach under extreme operation conditions (pressure ratio and stage cut) up to 52 vol.\% $\mathrm{O}_{2}$ on the permeate side of the membrane or up to $99 \mathrm{vol} . \% \mathrm{~N}_{2}$ on the retentate side. When the membrane is operated at economically reasonable conditions the $\mathrm{O}_{2}$ concentration on the permeate side can be up to 40 vol.\%.

Newly synthesized PVTMS samples showed $\mathrm{O}_{2}$ permeability coefficients of 7-16\% higher than the PVTMS-ref while the $\mathrm{O}_{2} / \mathrm{N}_{2}$ selectivity droped insignificantly (1-5\%). Tailor made polymers are usually showing properties better than polymers from mass production. The low polymer consumption required for the TFC membrane formation can justify the synthesis of only a few kilograms of such polymers per year to cover the industrial membrane demand.

The introduction of the polyisoprene block into the PVTMS matrix leads, however, to a significant drop in gas permeability. For the "simultaneous" and "sequential" block copolymers having PI spherical microdomains (PI content is $<10 \mathrm{wt} . \%$ ) there was no significant difference in properties and the total $\mathrm{O}_{2}$ permeability drop was $37 \%$ while the $\mathrm{O}_{2} / \mathrm{N}_{2}$ selectivity remains on the PVTMS-ref level. The lamellae forming block copolymers (PI content is $>20 \mathrm{wt} . \%$ ) caused up to $53 \%$ drop in $\mathrm{O}_{2}$ permeability. At high PI content a difference in permeability was also observed for the "simultaneous" and "sequential" block copolymers. The latter one displays a worse permeability which we believe to be related to a more perfect alignment of the lamellae parallel to surface, leading to a rather continuous layers of polyisoprene lamellae effectively blocking the permeation of gases. The "simulataneous" block copolymer displays a less ordered structure on a macroscopic scale and therefore shows more continuous paths or PVTMS domains across the membrane.

The presence of polyisoprene in the membrane does not affect considerably the $\mathrm{O}_{2} / \mathrm{N}_{2}$ selectivity. It appears that the much lower gas transport properties of polyisoprene $\left(\mathrm{P}\left(\mathrm{O}_{2}\right)=23.5\right.$ Barrer, $\alpha\left(\mathrm{O}_{2} / \mathrm{N}_{2}\right)=2.48$ [28] let it act as an impermeable additive to PVTMS. Thus mainly the permeability of the membrane is reduced without significantly affecting its selectivity.

\section{Conclusions}

A number of film forming polymers of pure PVTMS and block copolymers with polyisoprene were synthesized. An attempt to obtain a random copolymer by simultaneously copolymerizing isoprene and vinyl trimethylsilane revealed that due to faster polymerization kinetics of isoprene this monomer forms the first block followed by the PVTMS block. Depending on the chosen composition, spherical or lamellar structures were obtained as clearly visible on TEM images and by SAXS measurements. But despite the fact that these copolymers were not random at all, their gas transport properties were different from the corresponding block copolymer obtained by truly sequential polymerization in the lamellar case.

The polymerization technique allowed us to obtain yield of ca. 75 wt.\% with respect to conversion of VTMS and to obtain smaller final polydispersities than the ones reported in the literature.

The block copolymers have generally better film forming properties than pure PVTMS of the corresponding molecular weight, but show lower $\mathrm{O}_{2}$ permeability coefficients while the $\mathrm{O}_{2} / \mathrm{N}_{2}$ selectivities remain close to the one of pure PVTMS. A main advantage of these block copolymers is the fact that stable membranes can be formed for molecular weights significantly lower than those for film forming PVTMS.

The pure PVTMS polymers synthesized in this study have a low polydispersity and show $\mathrm{O}_{2}$ permeability superior to the more polydisperse reference polymer. Future work will include further reduction of the amount of 
polyisoprene in these block copoylmers in order to improve the film forming properties of PVTMS without loosing its gas separation performance.

\section{Acknowledgements}

The authors would like to thank Clarissa Abetz for the TEM investigations, Sérgio S. Funari (DESY) and Julio Albuerne for supporting the SAXS measurement, Silvio Neuman for the ${ }^{1} \mathrm{H}$-NMR measurements, and Peter F.W. Simon for GPC characterization and helpful discussions.

\section{References}

[1] French Pat. 1971; 2082095

[2] US patent 1973; 3729454.

[3] Yampolskii YP, Volkov VV. Studies in gas permeability and membrane gas separation in the Soviet Union. J Membr Sci 1991;64(3):191-228

[4] Durgar'yan SG, Yampolskii YP, Plate NA. Selectively permeable polymers and gas-separation membranes: structure and transport properties. Russ Chem Rev 1998;57(6):549-58.

[5] Brinkmann T, Hoting B, Wind J, Wolff T. Separation of $\mathrm{CO}_{2}$ from biogas by gas permeation. to be published In: Proceedings of the 13th Aachener Membran Kolloquium, Aachen, $27^{\text {th }}-28$ th October 2010.

[6] Gladkova NK, Durgar'yan SG. Synthesis of the AB type block copolymers (polyvinyltrimethylsilane-polydimethylsiloxane). Polym Sci USSR 1984;26(7):1642-8.

[7] Durgar'yan SG, Filippova VG. Synthesis and properties of three-block copolymers poly(dimethylsiloxane)-poly(vinyltrimethylsilane)poly(dimethyl-siloxane). Polym Sci USSR 1986;28(2):364-70.

[8] Filippova VG, Nametkin NS, Durgar'yan SG. Copolymerization of vinyltrimethylsilane with styrene in the presence of butyllithium. Russ Chem Bull 1966;15(10):1670-3.

[9] Durgar'yan SG, Filippova VG. Thermoplastic block copolymers of vinyltrimethylsilane with conjugated dienes and method of their making. USSR Patent 1978, 1166491.

[10] Uhrig D, Mays JW. Experimental techniques in high-vacuum anionic polymerization. J Polym Sci Part A Polym Chem 2005;43(24):6179-222

[11] Hadjichristidis N, Iatrou H, Pispas S, Pitsikalis. Anionic polymerization: high vacuum techniques. M. J Polym Sci Part A Polym Chem 2000;38(15):3211-34.
[12] Worsfold DJ, Bywater S. Anionic polymerisation of isoprene. Can J Chem 1964;42(12):2884-92.

[13] Nametkin NS, Semenov OB, Durgar'yan SG, Skazka VS, Filippova VG, Nikolayev VY. Determination of the molecular weight distribution of linear and branched polyvinyltrimethylsilanes. Polym Sci USSR 1975;17(5):1115-22.

[14] Shishatskii SM, Yampolskii YP, Peinemann KV. Effects of film thickness on density and gas permeation parameters of glassy polymers. J Membr Sci 1996;112(2):275-85.

[15] Shishatskiy S, Pauls JR, Pereira Nunes S, Peinemann KV. Quaternary ammonium membrane materials for $\mathrm{CO}_{2}$ separation. J Membr Sci 2010;359(1-2):44-53.

[16] Rangou S, Avgeropoulos A. Synthesis of dendritic terpolymers consisting of polystyrene, polybutadiene, and polyisoprene with different isomerisms. J Polym Sci Part A Polym Chem 2009;47(6):1567-74.

[17] Khotimsky VS, Pivovarov PV. Metallation of poly(1-trimethylsilyl-1prop-1-yne) and poly(vinyltrimethylsilane) with superbases. Russ Chem Bull 2006;51(12):2248-54.

[18] Antipov EM, Polikarpov VM, Volkov VV, Frenkin EI. Structure of mesophase polyvinyltrimethylsilane. Polym Sci USSR 1991;33(10):2006-14.

[19] Henis JMS, Tripody MK. Composite hollow fiber membranes for gas separation: the resistance model approach. J Membr Sci $1981 ; 8(3): 233-46$.

[20] Avgeropoulos A, Paraskeva S, Hadjichristidis N, Thomas EL. Synthesis and microphase separation of linear triblock terpolymers of polystyrene, high 1,4-polybutadiene and high 3,4-polyisoprene. Macromolecules 2002;35(10):4030-5.

[21] Rangou S, Avgeropoulos A, Krikorian V, Thomas EL. Synthesis and self-assembly of 2nd generation dendritic homopolymers and copolymers of polydienes with different isomeric microstructures. Macromol Symp 2008;267:16-20.

[22] Brandrup J, Immergut EH (Eds.), Polymer Handbook, 4th ed. WileyInterscience: New York, 1999 p. VI/243.

[23] Antipov EM, Polikarpov VM, Semenov OB, Khotimskii VS, Plate NA. A mesophasic state in poly(vinyltrimethylsilane). Polymer Sci USSR 2002;32(10):2308-14.

[24] Williams DRM, Halperin A. Microphases of nematic diblock copolymers: reentry and finite size effects. Phys Rev Lett 1993;71(19):1557-60.

[25] Brandrup J, Immergut EH (Eds.), Polymer Handbook, 4th ed. WileyInterscience: New York, 1999 p. V/5.

[26] Bondi A. Phys. Properties of Mol. Cryst. Liquids and Gases. Wiley: New York; 1968.

[27] Bernardo P, Drioli E, Golemme G. Ind Eng Chem Res 2009;48(10): 4638-63.

[28] Brandrup J, Immergut EH (Eds.), Polymer Handbook, 4th ed. WileyInterscience: New York, 1999 p. V/554. 